\title{
Risk Factors in Cost Estimation: Building Contractors’ Experience
}

\author{
Harriet Eliufoo* \\ Ardhi University, School of Architecture, Construction Economics and Management, \\ Building Economics Department, P. O. Box 35176, Dar es Salaam, Tanzania \\ *Corresponding author: heliufoo@yahoo.com, harriet@aru.zc.tz
}

\begin{abstract}
The study has examined risk factors in cost estimation of building construction projects. An investigation was made of risk emanating from risk factors as perceived by building contractors. Data was collected by use of questionnaires were a total of 61 questionnaires were administered to building contractors. The analysis considered four categories of risk factors: construction, physical, financial and estimator's risk factors. The results show estimator's risk factors as perceived to have the highest risk on cost estimates. Overall respondents view indicate all four categories of risk factors have an influence to project performance at a range of moderate to high. The study has also established potential risks that originate from risk factors. Such risks are noted to work against the achievement of project goals and include amongst others, project delays, cost overrun and performance failures. It is hence recommended by the study for not only contractors to be vigilant in mitigation of risk factors, but clients as well should also take this initiative as they are bound to suffer when inaccurate cost estimates are committed to a project.
\end{abstract}

Keywords: risks, risk factors, cost estimates, building construction

Cite This Article: Harriet Eliufoo, “Risk Factors in Cost Estimation: Building Contractors’ Experience.” American Journal of Civil Engineering and Architecture, vol. 6, no. 3 (2018): 123-128. doi: 10.12691/ajcea-6-3-5.

\section{Introduction}

Project goals in buildings are typically geared towards time, cost and quality it is hence prudent that contractors maintain a position for identification and mitigation of potential risks that may divert achievement of project objectives. Such strategy should commence at the early planning stages and for a contractor, at the cost estimation stage. Although all business ventures or projects are inherent of risks, the construction industry is relatively more prone to uncertainties compared to other industries; furthermore the industry is viewed as slow to adopt risk management practices [1]). This shortcoming makes the industry loose potential gains inherent in application of risk management procedures [2]. Failure of most construction projects to complete in the agreed time and budget is alleged attributed to risks inherent in construction projects $[3,4]$.

As cost estimation of construction projects is done under great uncertainty, it is of interest then to examine risk factors in cost estimation of building construction projects so as to have strategy for mitigation. This is important as accurate cost estimates are linked to project success [5] and [6].Accurate cost estimates are acknowledged as key for contractors to remain competitive in business [7]. The significance of accurate cost estimates in the construction industry cannot be overemphasized; as cost estimates are an integral component in the prioritization, planning and control of development projects. Tanzania like many other developing countries invests a substantial amount of development funds in the construction sector. For Tanzania the investment spending is reflected in its Gross Fixed Capital Formation (GFCF) that has been on the increase since independence. This is a scenario typical for developing countries where investment in infrastructure uses a big chunk of a country's development budget. Figure 1 illustrates how the Tanzania Gross Fixed Capital Formation had multiplied in an 8 - year period (2008 to 2016). The government of Tanzania for the fiscal year 20162017 had for instance budgeted for USD 2,420,353,982.30 (TZS.5.47 trillion) equivalent to $25.4 \%$ of its total budget, excluding public debt services, for infrastructure development (Tanzania-construction-sector-report, 2017).

Henceforth, to obtain value for money invested, it is imperative for actors in the industry to develop strategies so as to have accurate cost estimates for construction projects

The purpose of an estimate for a construction project is to postulate required cost for project completion in accordance to contract requirements [8]; it also serves a key function for securing new contracts hence providing opportunity for a contractor to remain competitive in business [9]. The diverse role of project cost estimates have been given in Weatney as cited in [10] and [11] who acknowledge its use not only limited to bidding, but also to other development activities. 


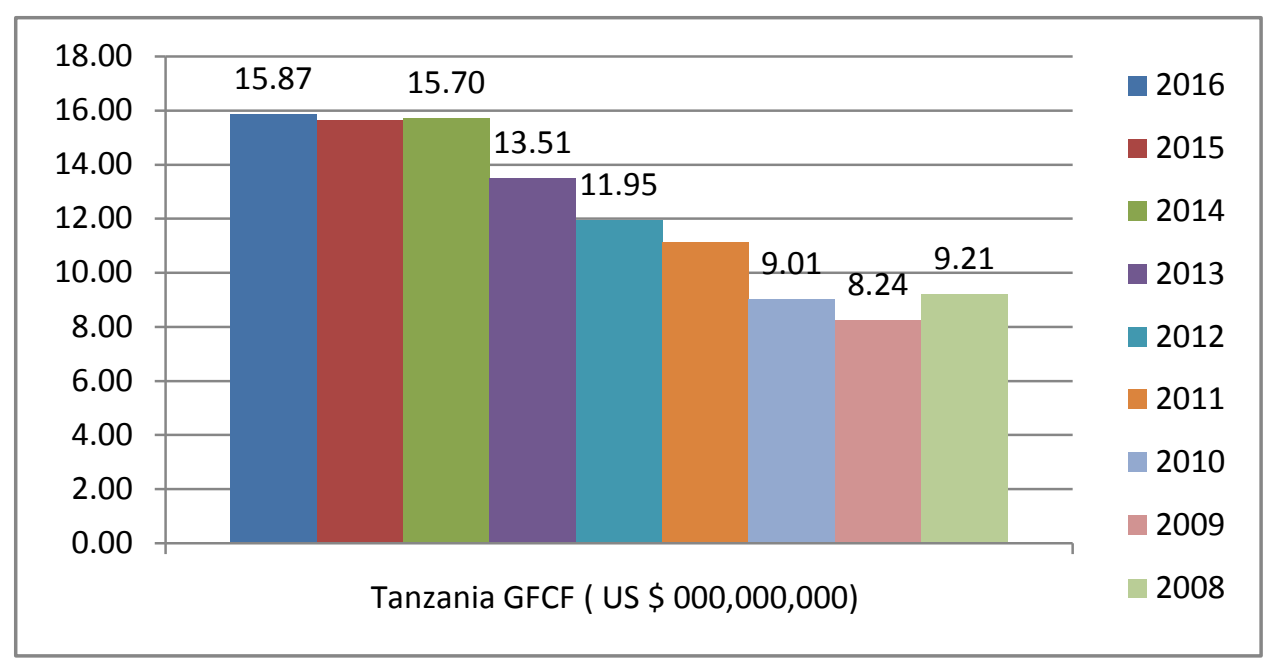

Figure 1. Tanzania Gross Fixed Capital Formation (2008- 2016), Source, National Bureau of Statistics, Tanzania

\section{Risk Factors in Construction}

Risk factor is explained as an attribute, or characteristic that increases likelihood of loss and may lead to changes as far as objectives are concerned [12]. Defined [13] as a potential complication or problem which can affect project objectives. Also as an uncertain future event or condition with an occurrence rate of greater than $0 \%$ but less than $100 \%$ that will have an undesired effect on at least one of the project objectives.

Failure to evaluate risk factors during cost estimation of construction projects jeopardizes a contractor's capability to finish a job. Identification of risk factors surrounding achievement of project goals has hence been the motivation for the study undertaken. Specifically the study has identified and prioritized risk factors during the cost estimation stage by building contractors. Building contractors' organizations have been taken as the subject of study based on the concept given in [14] of the existing relation between risk factors, risk outcomes, and organizational practices.

Factors influencing the accuracy of cost estimates as identified in [15] have included financial matters, bidding situations, project characteristics and applied estimating procedures. Availability of design information, type and quality of cost data, project type, project size, number of bidders, market stability, personal factors, skillfulness in estimating have likewise been mentioned as influencing factors $[7,16,17]$.

Approaches towards mitigation of risk factors in cost estimation have been suggested [18]. Conducting risk identification is suggested as one of the mitigation, defining the project risk factors in costs of previous projects, identifying unknowns at estimation stage that later became margin killers and using this knowledge for future cost estimation are amongst those identified [19]. Carrying out value engineering, having risk management plans purported as strategy towards mitigation [20]. Contractor awareness of the external environment requirements during cost estimation and subsequent consideration of external factors such as regulatory authorities' requirements could also avert risk occurrence [21]. Risk averse strategies during bidding process have also been discussed in [22]. Sub-contracting wherever possible, seeking more information to reduce uncertainty, taking insurance covers, and on the extreme, avoidance or declining a bid invitation when the risk is viewed beyond tolerance level have also been mentioned as potential mitigation measures [23].

\subsection{Risk factors in cost estimation}

The article has adopted categorization of risk factors in cost estimation as given in [7,12] and [25]. Risk factors in cost estimation have been identified [12] as constituting construction risk factors, physical risk factors and financial risk factors. Construction risk factors in cost estimation explained as risk factors related to plant/equipment or labor. This kind of risk could be in terms of accessibility to plant or equipment and also implicate: suitability of equipment, operational skills of operator and plant or equipment breakdown. For labor may encompass availability of skilled and experienced labor, labor force strike, management skills, material availability and supplier insolvency. These construction risk factors are purported, to extend to unexpected adverse site conditions [12].

Physical risk factors in cost estimation are factors related to physical nature of the project that can result to changes or damages to the building project. They include: design changes, insufficient details, bad weather, accidents, and theft of materials ([12]. Financial risk factors were explained to include, inflation in prices of materials and goods, fluctuations, and cash flow stability. With regard to estimator's risk factors these have been linked to: nature of competition, contract period, completeness of drawings and specification, completeness of project scope definition, foreseeable changes in materials, and design, current workload, errors in judgment, availability of data base from previous works and experience in particular projects [7] and [25].

\section{Data Collection and Analysis}

Data collection was limited to Dar es Salaam City, which is the commercial capital city of Tanzania, and is the most active region for construction activities. The 
population under study for this research was registered building contractors who are operating in Dar es Salaam City. According to the Tanzania Contractor's Registration Board (TCRB) directory (2017) the total number of building contractors who are operating in this City is 1330 . The population was narrowed to building contractors class I and Class II as their level of risk is relatively high due to huge capital investment that they may manage. As per the TCRB value of work limitation for a single project for each class of contractor, for Class II the maximum value allowed for a single project is equivalent to USD $\$ 1,363,636$ ( TZS 3,000,000,000 at an exchange rate of $1 \mathrm{USD}=$ Tzs. 2,200 year 2017). Class I have the liberty of unlimited value of work for any single building contract (CRB, 2017). The total number of registered building contractors in both classes based in Dar es Salaam was 131 and 31respectively; hence totaling to 162.

Sample size

The sample size was computed using Slovin's (1960) formula (www.statisticshowto.com/how-to-use-slovins-formula/).

$$
\text { Formulae } \mathrm{n}=\frac{\mathrm{N}}{\left(1+\mathrm{N} * \mathrm{e}^{2}\right)}
$$

Where; $\mathrm{N}=$ Total population size, $\mathrm{e}=$ margin of error, $\mathrm{n}=$ sample size

$\mathrm{N}=162$, Margin of error $(\mathrm{e})=0.1$, sample size $(\mathrm{n})=162$ / $\left(1+162 * 0.1^{2}\right)=61$.

Sampling techniques

The study used stratified random sampling for the two classes of building contractors. Based on the sample size of 61 building contractors, the number from each stratum was proportionately established as follows:

For class I building contractors $=131 / 162 \times$ sample size, $131 / 162 \times 61=49$.

For class II building contractors= 31/162 x sample size, $31 / 162 \times 61=12$.

Hence the sample size drawn from each stratum was 49 for class I and 12 for class II.

Fish bowl sampling technique [26] was subsequently used. The Likert scales on a scale of 1 to 5 was adopted and used to collect and analyze data from questionnaires. Relative importance of the risk factors was established by use of mean scores. The mean index formula (MS) from Stat (2017) list of statistical formula was computed:

$$
\text { MS. }=\Sigma(\mathrm{fxS}) / \mathrm{N}
$$

Where:

MS = Mean score

$\mathrm{f}=$ Frequency of response

$\mathrm{s}=$ Score assigned (1 to 5$)$

$\mathrm{N}=$ Total number of response
This ranking made it possible to compare the relative importance of the items as perceived by the respective respondents. The weighted average for each item for the respondents was determined and ranks $(R)$ were assigned to each item representing the opinion of the respondent. The relative importance index was calculated for each item by using the following formula

$$
\mathrm{RII}=\frac{\sum \mathrm{W}}{\mathrm{AN}}
$$

where: $\mathrm{W}=$ weight given to each statement by the respondents.

A = Highest score, which is 5

$\mathrm{N}=$ Total number of the respondents.

A total of 61 questionnaires were administered to respondents and the response rate obtained was $77 \%$ and $23 \%$ for Class I and II building contractors respectively. The questionnaire comprised five key areas of focus. The first part collected general information of the respondent; which inquired qualification of the respondent, occupation and number of years working in building projects. The second part targeted a collection of views from respondents on risk factors in cost estimation, where 24 risk factors were listed. The third part was designed for collecting respondents' experience on risks in building projects that originate from risk factors. The last part of the questionnaire targeted collection of potential mitigation measures of risk factors in cost estimation as viewed by respondents.

\subsection{Analysis and Discussion}

i) Construction risk factors in cost estimation

Eight risk factors identified in [12] were used with the aim of identifying construction risk factors in cost estimation as experienced by contractors in Tanzania. The results are shown in Table 1.

The results showed the highest risk factor under this category, was "unexpected adverse site conditions" having the highest mean score; followed by "levels of labor productivity” that came second in rank. An unexpected adverse site condition with a mean score of 4.08 is in the grading position of "very important factor". Labor productivity, suitability of plants and equipment, availability of materials were ranked as moderately important with mean scores ranging between 3 and 4 .

The interpretation made is that the three risk factors, namely unexpected adverse site conditions, labor productivity levels and suitability of plants and equipment are key risk factors to be taken into consideration during cost estimation. From the results it was noted that labor force strike had the lowest mean score implying it is being

\begin{tabular}{|c|c|c|c|c|c|c|c|c|}
\hline Construction Risk Factors & 1 & 2 & 3 & 4 & 5 & Mean score & RII & Rank \\
\hline Unexpected adverse site condition & 0.0 & 2.0 & 6.0 & 19.0 & 14.0 & 4.08 & 0.82 & $1 \mathrm{st}$ \\
\hline Productivity of laborers & 1.0 & 6.0 & 13.0 & 15.0 & 5.0 & 3.42 & 0.67 & $2^{\text {nd }}$ \\
\hline Suitability of plants/ equipment & 4.0 & 3.0 & 20.0 & 11.0 & 3.0 & 3.14 & 0.63 & $3^{\text {rd }}$ \\
\hline Materials availability & 0.0 & 11.0 & 17.0 & 12.0 & 1.0 & 3.07 & 0.61 & $4^{\text {th }}$ \\
\hline Familiarity to tasks & 4.0 & 6.0 & 18.0 & 9.0 & 4.0 & 2.68 & 0.53 & $5^{\text {th }}$ \\
\hline Equipment break down & 4.0 & 16.0 & 11.0 & 9.0 & 1.0 & 2.68 & 0.53 & $5^{\text {th }}$ \\
\hline Labor skill/ experience & 5.0 & 6.0 & 17.0 & 12.0 & 1.0 & 2.67 & 0.52 & $6^{\text {th }}$ \\
\hline
\end{tabular}
perceived to have the least influence in cost estimates.

Table 1. Construction risk factors in cost estimation 
Table 2. Physical risk factors in cost estimation

\begin{tabular}{|l|c|c|c|c|c|c|c|c|}
\hline Physical risk factors & $\mathbf{1}$ & $\mathbf{2}$ & $\mathbf{3}$ & $\mathbf{4}$ & $\mathbf{5}$ & Mean score & RII & Rank \\
\hline Incomplete design/ specifications & 0.0 & 0.0 & 20.0 & 15.0 & 6.0 & 3.65 & 0.73 & $1 \mathrm{st}$ \\
\hline Design changes & 0.0 & 4.0 & 17.0 & 16.0 & 4.0 & 3.48 & 0.69 & $2 \mathrm{nd}$ \\
\hline Site security & 0.0 & 2.0 & 28.0 & 4.0 & 7.0 & 3.42 & 0.68 & $3 \mathrm{rd}$ \\
\hline Design errors/ specification & 0.0 & 4.0 & 24.0 & 5.0 & 8.0 & 3.41 & 0.66 & 4 th \\
\hline Fire accidents loss & 0.0 & 14.0 & 18.0 & 3.0 & 6.0 & 3.02 & 0.60 & 5 th \\
\hline Bad weather & 2.0 & 6.0 & 27.0 & 3.0 & 3.0 & 2.97 & 0.59 & 6 th \\
\hline Operative accidents & 2.0 & 6.0 & 27.0 & 3.0 & 3.0 & 2.97 & 0.59 & 6 th \\
\hline
\end{tabular}

Table 3. Estimator's risk factors in cost estimation

\begin{tabular}{|c|c|c|c|c|c|c|c|c|}
\hline Risk factors & 1 & 2 & 3 & 4 & 5 & Mean score & RII & Rank \\
\hline Incomplete scope definition & 0.0 & 0.0 & 1.0 & 11.0 & 27.0 & 4.45 & 0.89 & $1 \mathrm{st}$ \\
\hline Tendering period & 0.0 & 0.0 & 3.0 & 17.0 & 21.0 & 4.43 & 0.83 & 2nd \\
\hline Cost data quality & 0.0 & 0.0 & 11.0 & 21.0 & 9.0 & 3.95 & 0.79 & 3rd \\
\hline Access to site & 0.0 & 0.0 & 15.0 & 19.0 & 7.0 & 3.80 & 0.76 & 4th \\
\hline Estimating skill & 1.0 & 0.0 & 17.0 & 14.0 & 9.0 & 3.69 & 0.74 & 5th \\
\hline Current work load & 0.0 & 6.0 & 14.0 & 19.0 & 2.0 & 3.46 & 0.68 & 6th \\
\hline
\end{tabular}

Table 4. Financial risk factors in cost estimation

\begin{tabular}{|l|c|c|c|c|c|c|c|c|}
\hline Financial risk factors & $\mathbf{1}$ & $\mathbf{2}$ & $\mathbf{3}$ & $\mathbf{4}$ & $\mathbf{5}$ & Mean score & $\mathbf{R I I}$ & $\mathbf{R a n k}$ \\
\hline Funding uncertainty & 1.0 & 3.0 & 6.0 & 16. & 15 & 4.0 & 0.8 \\
\hline Inflation & 1.0 & 4.0 & 11. & 17. & 8.0 & 3.65 & 0.73 \\
\hline Market stability & 1.0 & 12. & 16. & 5.0 & 6.0 & 3.07 & 0.60 \\
\hline
\end{tabular}

Identification of adverse site condition as the highest factor from the list of identified risk factors corresponds with studies that had found difficulty and unexpected adverse site conditions was an inflating factor to contractor's pricing during tendering [27].

ii) Physical risk factors in cost estimation

Six physical risk factors in cost estimation were examined with respect to significance, by the respondents. Chronologically, significant risk factors in cost estimation under this category as reported by contractors was, incomplete design and specifications, design changes, and site security. The least important risk factors were reported to be bad weather and operative accidents. Refer Table 2. What is noted is that mean scores of all risk factors is above 2.5, implying that contractors view the significance of these factors as moderately important. No factor however was viewed as "very important”.

iii) Estimator's risk factors

Six estimator's risk factors as given in [7,25] and [28] were used to collect contractors' view on the significance they place on such risk factors. These risk factors were incomplete scope definition, quality of cost data, skillfulness in estimating, current work load, access to site, and tendering period. See Table 3.

The results showed the most significant risk factors in cost estimation chronologically are: incomplete scope definition, tendering period, and quality of cost data while the least factor being current work load. However of interest in these results is the significance contractors put on the estimating factors; as it is noted with an exception of one risk factor, of current work load, all scored a mean of above 3.5. This indicates all estimating factors are considered important and tendering period and incomplete scope definition reported to be very important, with mean scores above 4.0 .

iv) Financial risk factors

Under this category three financial risk factors were presented to contractors requiring them to weigh in terms of their importance in cost estimation. These were, funding uncertainties, inflation, and suitability of market conditions. Under financial risk factors, the identified risk factor with the highest mean score is funding uncertainties while stability of market condition scored the least, meaning that funding uncertainties is perceived as the greatest risk factor for building contractors in cost estimation. Refer Table 4.

\subsubsection{Risks in Building Construction Projects Emanating from Risk Factors in Cost Estimation}

Data was collected and analyzed to obtain the perception of building contractors of what they identify as risks that occur in building construction projects that originate from cost estimation risk factors.

For construction risk factors in cost estimation potential risks in project identified by respondents included buildability complications, project delays, construction cost overrun, project delays and tight schedule which may lead to low quality work. With respect to physical risk factors in cost estimation, resulting risks identified by respondents as possible to occur included changes in requirements or design, undocumented change orders, theft or loss of materials and equipment, project delays, varied labor and equipment productivity. For estimator's risk factors in cost estimation, resulting risks included 
liability challenges as scope does not clearly define where liability starts and finishes, rushed bids, poor judgment, inadequate program scheduling, inaccurate cost estimates and failure to meet delivery schedules. Financial risk factors in cost estimation, resulting risks as viewed by the contractors included, contractor failure to perform, interest charges changes and price fluctuations.

What is being noted is that, adverse effect of cost estimation risk factors has potential of jeopardizing achievement of construction project goals.

\subsubsection{Approaches towards Mitigation of Risk Factors in Cost Estimation}

Based on respondents' views, the most effective way of mitigating risk factors during cost estimation is 'understanding of the project's external environment" while the least strategy is 'withdrawal from tendering'. The "use of tools and techniques for determination of likelihood of risk' came second in rank with a mean score of 3.26, and the third mitigation measure suggested was "inclusion of a sufficient contingency amount in estimates". It is noted, with an exception of understanding the project environment, other mitigation measures are viewed as moderately effective.

\section{Conclusion}

As risk factor is an attribute, or characteristic that increases likelihood of loss and can lead to changes as far as objectives are concerned [12], the investigation has shown contractors are aware of cost estimation risk factors related to construction. The investigation has established all four risk factors, construction, physical; estimators and financial risk factors have an influence on the accuracy of cost estimates of building construction projects and are important. The study has also established the top ranked factors are estimator's risk factors and financial risk factors. That, incomplete scope, limited tender period and quality of cost data have a significant influence in the accuracy of cost estimates; followed by funding uncertainties and inflation. Moreover, not only respondents have shown awareness of cost estimation risk factors in building construction projects, but have also expounded their potential risks to building projects. These risks emerging from risk factors include amongst others project delays, cost overruns and unrealistic tight schedules that may result to low quality work. As it may be noted these resulting risks, are in conflict to key construction project goals of time, cost and quality.

\subsection{Implication to Construction Industry}

The outcome of the research is further noted to have implication beyond construction firms. This is so since the study has established the outcome of the risk factors, affects other parties to the project as well. Outcomes such as project delays, low productivity, and failure to accomplish scheduled tasks are some of the outcomes that not only affect negatively the contractor but project clients' as well.

In most developing countries, the major client is the Public client; hence the implication is that public funds are subsequently not committed to good use. It is hence of interest for construction industry stakeholders to be conversant with mitigation measures of risk factors and seek to deploy them. Certain governments initiatives through regulatory bodies has examples of by-laws and regulations that though may not by intent, serve as mitigation measures for some of the risk factors. Minimum time set by the Tanzania Public Procurement Authority Regulation (2013) for contractors to bid as appearing in its Eighth Schedule [27] functions as a mitigation measure. Furthermore it is also in the interest of contractors themselves to thrive towards adoption of mitigation measures of cost estimating risk factors as established from the study, as they are prone to suffering greater loss compared to other parties in the project. Studying the project's external environment is crucial towards this end.

\subsection{Limitation of Study and Generalizability}

Although the study has limited itself to Tanzania, a developing country it is however acknowledged that the implications go beyond this geographical and economic limitation. This is so as risk factors whether physical, construction or estimator's, are inherent in any construction project venture.

Furthermore, despite the author taking the stance that high class building contractors carrying large investments, are at a position to be relatively more affected by risks, the selection of contractors from Class I and II only is viewed as one of the study's limitation. The author acknowledges that risk factors manifestation is not class bound that building contractors in other classes are also prone to these factors. The other limitation is that the study has only focused in building contractors in Tanzania with ongoing projects in Dar es Salaam. Contractors working outside Dar es Salaam and in other countries with similar economies are susceptible to these risk factors as well. However, despite the spatial limitations, the results are viewed by the author to have opened up an awareness advocacy for mitigation of risk factors during the cost estimation process.

\section{Acknowledgements}

An acknowledgement is made to the research assistants that had provided support to the data collection process.

\section{References}

[1] Flanagan, R. and Norman, G. (1993). Risk Management and Construction, Wiley- Blackwell.

[2] Cullen, S. (2012). Risk Management, retrieved from wbdg.org: http://www.wbdg. Org/ project/ riskmanage.php, accessed December 5, 2017.

[3] Chileshe, N. and Kikwasi, G.J. (2013). "Perception of barriers to implementing risk assessment and management practices by construction professionals in Tanzania”, In: Smith, S.D and Ahiaga - Dagbui, D.D (Ed), Procs 29th. Annual ARCOM Conference, 2-. 4 September 2013, Reading, UK

[4] Al-Bahar, J.F. and Crandall, K.C. (1990). "Systematic risk management approach for construction projects”, Journal of Construction Engineering and Management, 116(3), pp.533-546.

[5] Wang, W.C., Wang, S.H., Tsui, Y.K. and Hsu, C.H. (2012). “A factor-based probabilistic cost model to support bid-price estimation”, Expert Systems with Applications, 39(5), pp.5358-5366. 
[6] Enshassi, A., Mohamed, S. and Madi, I. (2007). "Cost estimation practice in the Gaza Strip: A case study”. IUG Journal of Natural Studies, 15(2), pp. 153-176

[7] Akintoye, A. and Fitzgerald, E. (1999). "A survey of current cost estimating practices in the UK”, Construction Management \& Economics, 18(2), pp.161-172.

[8] Abdal-Hadi, M.A. (2010). Factors affecting accuracy of pre-tender cost estimate in Gaza Strip. Unpublished master thesis in construction management, The Islamic University of GazaPalestine.

[9] ElSawy, I., Hosny, H. and Razek, M.A. (2011). "A neural network model for construction projects site overhead cost estimating", Egypt, International Journal of Computer Science Issues (IJCSI), $8(1)$.

[10] Marjuki, M. (2006). Computerized building cost estimating system, Master's thesis, University Technology Malaysia, Faculty of Civil Engineering.

[11] Jitendra, V. and Kuldeep, S. (2011). "Cost prediction using Neural Network Learning Techniques”, IJCSMS International Journal of Computer Science and Management Studies, Vo. 11(02). IJCSMS International Journal of Computer Science and Management Studies, Vol. 11(2), Aug 2011 ISSN (Online): 2231-5268 www.ijcsms.com IJCSMS retrieved November 2017.

[12] Chapman, R.J. (2001). "The controlling influences on effective risk identification and assessment for construction design management”, International Journal of Project Management, 19 (2001), pp.147-160.

[13] Rezakhani, P. (2012). "Classifying key risk factors in construction projects" Bulletin of the Institute of Polytechnic Institute of Jassy, Construction Architecture section 58(2), p.27-38.

[14] Jannadi, O.A. and Almishari, S. (2003). "Risk assessment in construction”, Journal of construction engineering and management, 129(5), pp.492-500.

[15] Shash, A., and Abdul-Hadi, N.H. (1993), "The Effect of Contractor Size on Mark-up Size Decision in Saudi Arabia", Construction Management and Economics, Vol. 11., PP421-429.
[16] Ashworth A. (1994). Cost studies of Buildings, Addison Wesley Longman Ltd.

[17] Shash A. and Nader Husni Abdul-Hadi (2006). "The effect of contractor size on mark-up size decision in Saudi Arabia", Construction Management and Economics, 11:6, 421-429.

[18] Rupen Sharma (2014). Tips for accurate cost estimates, retrieved from

http://www.brighthubpm.com/project-planning/102898-taming-the unknown-accurate-cost-estimates-tips. Accessed in November, 2017.

[19] OBS, (2017). Oldcastle Building solutions, Tips for accurate construction project estimate, retrieved from http://www.buildingsolutions.com , accessed June 8, 2017.

[20] Holloway, S. (2013). Conceptual construction cost estimating, retrieved from The Holloway Consulting Group Website: http://www.hcgexperts.com/contractors-risks-in-conceptualestimating-part-1.php, accessed March 172017.

[21] Cheri, H and Daniel (2015). Seven ways contractors can manage cost escalation, Retrieved from http://www.XLGroup Ltd.com, accessed in June 13, 2017.

[22] Laryea, S. and Hughes W. (2008). "How contractors price risk in bids: theory and practice”, Journal of Construction Management and Economics, 26, 911-924.

[23] Abu Rizk, S, (2003). Risk and uncertainty in construction: an overview retrieved from www.websrv.construction. ualberta.ca/papers \& presentations.

[24] Shash, A. A. (1993). "Factors considered in tendering decisions by top UK contractors", Construction Management and Economics, 11(2): 111-18

[25] Kumar R. (2005), Research Methodology a step by step guide for beginners, Sage Publications.

[26] Wong, J. T. Y. and Hui E. C. M. (2010). "Construction project risks: further considerations for constructors' pricing in Hong Kong”, Construction Management and Economics, 24:4, 425-438.

[27] United Republic of Tanzania, The Public Procurement Regulation (2013). Government Printer, Dar es Salaam. 